\title{
After Feminism: Taking Human Diversity Seriously
}

\author{
Michael Warby
}

N Australian woman in early adulthood can expect to live five years and
seven months longer than her male compatriots. This is partly because a
male is 80 per cent more likely to be murdered, 140 per cent more likely to die in a car accident and 330 per cent more likely to commit suicide. Furthermore, a male worker is 1,045 per cent more likely to be killed in a work accident and 150 per cent more likely to be injured at work. A male is also 35 per cent more likely to be subject to assault. 'The young Australian woman has the full right to vote, own property and pursue a career. Tribunals of state staffed by committed officers stand by to protect her against acts of sexual discrimination. If she is in higher education, she is in the majority gender (since 1986) for Australian higher education students. She is a fortunate member of the most prosperous and longest-living generation of women in history, and the one with the broadest opportunities.

Female experience in Australia is hardly even largely one of oppression or deprivation, whether compared with her male compatriots or with women in other lands or other times. This is not to deny the existence of discrimination against women; it is to say merely that the gender situation in contemporary Australia is complex and any model that presumes oppression and deprivation is a completely inadequate basis for analysis. (And the more successful feminism is, the less adequate such a model must become.)

Several recent writers have felt that many feminists no longer speak to the social world as it actually is (Roiphe, 1994; Wolf, 1993; Sommers, 1994; Denfeld, 1995; Taylor, 1992). They write in revolt against the type of feminism that they call, variously, 'victim feminism', 'gender feminism' and 'the new Victorians'. This sudden

\footnotetext{
Cause of death rates per 100,000 for men and women respectively in 1993: homicide 2.4 and 1.3, suicide 19.2 and 4.4, motor vehicle accidents 15.7 and 6.5 (ABS Cat. Nos. 3101.0, 3302.0). Proportion of population subject to assault in twelve months to April 1993 as measured by the ABS's 'Crime and Safety' survey: 2.4 per cent of males and 1.8 per cent of females (including 0.4 per cent sexual assault: the sexual assault question was not asked of males) (ABS Cat. Nos. 3101.0, 3102.0, 4509.0). Wage and salary eamers per work death in 1991-92: for men 8,451; for women 96,745. Wage and salary eaniers per work injury in 1991-92: for men 29, for women 73 (ABS Cat. No. 6203.0; Compendium of Worker's Compensation Statistics 1991-92.
}

Michael Warby is Public Affairs Manager of the Tasman Institute. He is currently on leave from the Commonwealth Parliamentary Library. 
flowering of largely youthful dissent follows the explosion on to the media scene of egomaniac and critic Camille Paglia (1991, 1993, 1994), who has criticised common feminist positions on subjects such as date rape and pornography. These writers are, in their different ways, all much concerned with the gap between attitudes of the general female population in the West, particularly in Anglo countries, and the ideas and assumptions that are powerful in feminist networks: what is sometimes known as the 'I am not a feminist, but . . ' phenomenon, where women identify with equal opportunity but not feminism.

Economic analysis can throw interesting light on this, and the issue of discrimination more generally, particularly if a couple of common analytical errors are avoided. This provides a basis for examining some of the important underlying philosophical issues that are driving the debate, as well as for avoiding certain intellectual errors.

\section{The Plausibility of Discrimination}

Economists can easily fall into the generaliser's error of assuming too great a simplicity of causes. A classic case of this was the Mises-Hayek criticism that socialism was impossible because of its inability to engage in economic calculation. We can see now that Mises and Hayek were essentially correct, but the collapse of socialism simply took far longer than they implied due to factors such as the countervailing effect of black markets and the low intensity of competition between states.

Nevertheless, despite failing to take into account the messiness of social phenomena (particularly the ability of people and institutions to 'make adjustments' to cope with even debilitating underlying tendencies), Mises and Hayek did what good economics does: identify underlying tendencies, directions in which the phenomena will tend to move. Events will move more or less quickly in that direction, depending on such factors as decision cycles and the constraints and pressures on agents, and the strength of the pressures to find (and possibility of achieve) optimising outcomes.

Another easy economist's error is to assume too great a level of deliberate, continuous calculation in human behaviour. In practice, people are not continuous calculators. Instead, they use habits, routines, prejudices: the rational results of economising on time and mental effort. Experienced changes in circumstances are far more likely to engender calculation than the continuation of familiar circumstances. There clearly is such a thing as social inertia. Thus, discriminatory behaviour can persist, even when gains exist to be captured by hiring 'out group' staff, if pressure to realise those gains is low: the more 'invisible' such gains are to prevailing attitudes, the higher the pressure to realise gains has to be before they will be acted upon. If there are what economists call 'principal-agent' problems, where decisions are made on behalf of others, the pressure on the decision-makers to realise such gains may be very low.

Discrimination can be viewed as a form of category (male, white, Protestant, etc.) cartel. Such cartel behaviour is made easier when general beliefs support it or circumstances (such as living in a small town) make enforcement easy. Nor should 
it be forgotten that there are psychic returns to awarding oneself moral superiority. Doing so on the basis of membership of some category, such as class, race, gender or sexuality, is hardly uncommon.

It is not necessarily a simple matter to identify genuine discrimination. Members of out-groups may be initially less productive, because of lower education, skills and experience. Unless they have compensating features, like the strong family networks of Chinese communities, they may also represent higher credit risks. Information flows, about business reputation, for example, may be much stronger within than between groups. What looks like discrimination may be sensible, even fair, market behaviour.

To complicate matters further, during periods of transition away from endemic discrimination there are cohort effects. If one assumes that the idea that women would have full careers similar to men became widespread by, say, 1975, then the distribution of positions typically involving long lead times (like senior management) currently occupied by people over 45 years of age is going to reflect the career assumptions of 1965 or 1955 , not those of 1995. As the post-1975 cohort moves through the workforce, the distribution of positions can be expected to change accordingly. Average gender incomes will also be affected. Separating cohort effects from discrimination is not always easy; often it is not done at all, particularly in public commentary (Rimmer, 1995).

\section{Household Optimisation}

The change in the lives and opportunities of women is, above all else, a change in the behaviour of, and within, households. There have been massive changes in constraints on Western households in optimising their use of resources over the last few centuries. In the medieval and early modern periods, error in household resource choices could lead not merely to dire poverty, but to starvation. This generated obvious pressure to conservatism: to the adoption of low-risk strategies, known to be successful, which minimised social difficulties. A result of dramatically increasing prosperity has been a massive increase in the capacity to innovate and explore different household strategies.

The concept of comparative advantage is one of the most powerful ideas in economics, since it explains the hugeness of possible gains from trade. It is easy enough to explain how A and B can trade for mutual benefit when each is better at different things. The great power of comparative advantage is that it allows $\mathbf{A}$ and $\mathbf{B}$ to trade to mutual advantage even when $A$ is better at everything than $B$. In the case of individuals, time scarcity is sufficient to produce that minimum result, with comparative advantage showing how trade can be optimised under the time constraint. Thus, a doctor will hire a cleaner to clean her office even when she could to a better job of it herself, because it is far more productive for her to devote her work time to earning a doctor's income than replacing the (far lower) wage of a cleaner.

But comparative advantage can explain not only why a doctor hires officecleaning services and why countries benefit from free trade. It can also shed light on household arrangements, their content, persistence and changes. In situations 
where child-rearing involves a major commitment of scarce resources, where life expectancies are low and where strength is strongly and widely connected with effectiveness in economic activity external to the home, then the appropriate household resource optimisation strategy is very likely to be for mothers to concentrate on home duties and fathers to engage in external economic activity. This would tend to reduce female bargaining power within households.

As child-rearing becomes less dominant in household resource use (as indicated, for example, by a falling incidence of the abandonment of children), as technological advance reduces the time demands of home duties and as external economic activity becomes based less on strength and more on dexterity and intelligence, then the demands of domestic activity become comparatively less important, and strength-based male advantage in external economic activity declines generally (and completely disappears over wide sections of the economy). The appropriate household optimisation strategies also change. Female bargaining power would also tend to increase.

A great deal of evidence shows that household strategies depend on the operating resource constraints, and that culture tends to evolve to ratify these strategies. Resource constraints have major implications for gender roles and male-female power balances. Feminism is thus not the result of Western women suddenly becoming individually smarter or more perceptive, though the knowledge stock clearly tends to increase from generation to generation. There are underlying economic reasons for the rise of feminism, though this burgeoning prosperity may well have bases in family structure and culture (Wilson, 1993).

\section{The Vanguard Role}

How do households find new strategies? What makes people reconsider customary choices, particularly choices supported by strong social taboos promoted by, for example, organised religion?

Some of this will simply be spontaneous personal experimentation. But since time, effort, costs and risks are inherent in untried strategies, this is unlikely to be a major source. Individuals with the leisure, resources or professional capacity for considering, articulating and advocating new strategies and possibilities are likely to be very important in generating ideas. One can therefore expect a fairly natural division between an activist 'vanguard' and a more cautious majority who adopt ideas, after a delay, if they resonate with their own circumstances. This does indeed seem to be the pattern of feminist history and of current feminism.

But note the 'if'. Not all ideas will be sensible. Not all with be useful. The vanguard is not going to be always right. Nor is the vanguard likely to be in any sense a monolithic group. Nor has it been, a point that more than one of the above critics (correctly) emphasises. Nor slould it be. To deny the right to diversity in

\footnotetext{
${ }^{2}$ Anthropologist Marvin Harris provides a severely materialist coverage of such evidence (Hanis 1990). James Q. Wilson provides a sophisticated survey of the evidence in Chapter 8 of Wilson (1993).
} 
ideas is to be extraordinarily confident that the full truth is already known. Again, there is obvious psychic return to seeing yourself as a member of a knowing elite, but human experience has not been kind to such pretensions: the grotesque failure of Leninism is a particularly egregious example.

Hostility to diversity in ideas is to be deeply distrusted. The critics of feminism listed above contend that the vanguard is trying to enforce a feminist 'party line'. The claim that 'error has no rights' leads directly to the persecution of opposing ideas, to the persecution of people, and to the attempt to systematically edit social reality so that it conforms to the 'revealed truth'. Claims to power based on knowledge are the most deeply tyrannical of all, simply because there is no limit in the social realm to what can be claim to be known, and therefore to what can be declared error and 'edited' accordingly. It is no accident that the medieval church, whose claim to social power was clearly based on a claim to know, pioneered the techniques of social control later modernised and extended by 20th-century totalitarianism. 'Political correctness' is the pre-eminent modern example of such a claim to know. Its power is easily exaggerated; but it is the power its adherents so obviously desire to have that is driving mucl of the reaction against them. They repeat the old Catholic doctrine that error has no rights (as with anti-vilification legislation, for example). And vanguard feminism is much involved in political correctness.

Even so, the mere existence of a gap between majority attitudles and the vanguard is not of itself a problem unless the vanguard is heading in a direction that the majority is unlikely to want to go. This is a common concen of the critics: much vanguard feminism is not concerned with the actual or likely problems of women, and is leading in directions where most women neither want to go, nor ought to go. With the creation of academic feminist networks, such as 'women's studies' courses and departments, and 'femocrat' institutions in the public service, such as the Office of the Status of Women (or the Office of Women of Status as it is sometimes known), such a division is quite likely. Activist academia and activist bureaucracy are very particular social circumstances, and there are no reasons to suppose that they provide automatic identification with general female experience and interests.

\section{A Common Moral Discourse?}

Indeed, rather the opposite. The general female interest is in a society in which women are as constrained as little as practical by their gender, where there is a general moral and social discourse in which all adults, male and female, participate as full members. For them, 'women's liberation', with its implication of a transition to a culminating endpoint of human equality, is much more in their interests than a continuing gender division. Their interest is in workable social solutions to the continuing, though patently diminishing, problems of gender discrimination against them. They also have a clear interest in workable parenting arrangements that are sensible and acceptable to mothers and fathers, and in the interests of children.

The reverse is true for the femo-academics and femocrats. They have an interest in a continuing, indeed expanding, vista of 'problems' from which they can gain kudos by identifying and 'addressing'; in extension of specifically 'female' discourses 
of which they, and they alone, are the experts and interpreters. A society of decreasing discrimination would be, for them, one of diminishing career opportunities and importance. The incentives they operate under encourage a perverse moral and intellectual entrepeneurialism. Hence the dissatisfaction of many of the critics, particularly Christina Hoff Sommers.

As discrimination against women lessens, specifically gender-based politics and discourse must lose their relevance (assuming, of course, it is not replaced by discrimination against men). If social rules and practices restrict women less and less, then women-as-women simply must have less and less in common that is distinctive from men.

\section{The Individualist Imperative}

Feminism suffers from the fundamental problem of any collectivist discourse: that we are not defined by any single one of the many different categories to which we belong. Any attempt to see category membership as morally defining must diminish us and lessen our humanity.

Individualism is not the claim that collective characteristics do not exist, that they do not matter, that they do not affect social outcomes, that they cannot be constraints or advantages; or that social relations do not matter, that we are not social beings, that social influences do not matter, or that they do not help form us. What individualism does claim is that no collective characteristic defines us. Seeing any particular characteristic as defining diminishes and dehumanises us, which is why serious collectivist reasoning - on the basis of race, gender, class, sexuality or whatever - is so intimately tied to oppression, tyranny and mass murder. For if ethical collectivism is accepted, we cease to be individual people, with all the complexity, diversity, specificity that entails, and become mere integers of categories with pre-assigned moral status. The search for a benign ethical collectivism is a search for the impossible: the thing contradicts itself. Individualism gets its moral power precisely from the fact that once people are not seen as merely integers of particular categories, one is irretrievably committed to taking individual wants, preferences and claims seriously. One is committed to the complexity, diversity and autonomy of people, to their worth-in-themselves. One is also committed to the existence, at least potentially, of a moral and social space in which all can interact as persons, and not be trapped in irredeemable isolation as members of mutually exclusive categories.

If feminism makes sense as anything other than a demand for privilege, it must be the attempt to take such gender-categorisation out of our moral and political discourse except in those very narrow areas where it will remain appropriate.

This is not to say there is no point to feminism. Far from it. What it is to say is that a single gender cannot be the central reference point for a satisfactory moral discourse about gender or one without gender. It is fair enough to start from a feminist perspective, especially as there are very interesting issues about use of language, about social interactions, about how images and self-images are framed 
(Travis, 1992), about real as opposed to apparent universalism (Gatens, 1991), and so on. It is just that a gender perspective can never be a satisfactory ending point.

Nor has it been so in practical politics. Feminist political achievements have always ultimately hung on appeals to a common humanity. Since women have not yet achieved representation in legislatures in line with their share of the population, every feminist breakthrough has come from deliberative bodies a majority of whose members, sometimes all of whose members, were men. The effective moral claim has not been 'we are women' but 'we are people'. In other words, the morally effective claim has been that gender is not an appropriate moral category in the matter (owning property, having the vote, entering a career, or whatever), that personhood is not defined by gender (or race, or sexuality, or whatever).

\section{Coalface Feminism}

Failing to grasp this is quite clearly a common, even natural, error in feminism. The major appeal of collectivist discourses is their simplicity: "we are better than you', 'you are responsible for our problems', 'we can talk about you as an undifferentiated lump'. Seeing the category in question as simply one of the many dimensions along which individuals can be aggregated is much more complex, and a lot less morally and emotionally satisfying.

That this fundamental moral error leads to other moral errors can be seen in aspects of what might be called 'coalface' feminism: the feminism of public debate and public policy. For example, discussion and operation of the 'battered spouse' defence has come perilously close at times to the claim that a woman who remains with a battering spouse at some point acquires the right to kill him even when not under immediate physical threat. This is not a claim of common moral adulthood.

One may also doubt whether the recent 'violence against women is wrong' campaign was really the best way of achieving the laudable ideal of reducing domestic violence. A campaign based, for instance, on the message that the home ought to be a sanctuary' would have the great advantage of drawing men in rather than excluding them. Even more to the point, it would not write battered husbands (yes, Virginia, there are such people) out of the social script (Thomas, 1993). Moving from a discourse that systematically discounts female claims to one that systematically discounts male ones is not a moral advance.

One may feel that violence against certain categories of people (such as babies or the aged) is particularly noxious, usually on the grounds of their sheer defencelessness. The past belief that women were subject to special consideration was directly tied to their status as being protected by, and legally subordinate to, men. To claim the rights of full adults yet also to claim the right to special consideration is hardly reasonable. The point should be that gender is not an appropriate moral category here, particularly as women are not, on average, more at risk of violence than men - though again the matter is complicated by the fact that men are more prone to put themselves, for whatever reason, in dangerous situations, while women are more at risk in domestic situations. 
These considerations indicate that the notion of 'representativeness' is somewhat morally suspect. The holders of risky jobs in our society are disproportionately male, as the vast disparity in workplace death indicates. These jobs have a risk premium that is one of the factors leading to unequal average incomes. It is not clear that it would be a moral advance to have women bearing such risks equally with men. It would certainly not be a moral advance if average incomes were equalised while the holders of such risky jobs remained overwhelmingly male (Farrell, 1994). The notion of 'representativeness' can easily imply that we are primarily integers of particular categories that have to be 'balanced', rather than full human beings who happen to belong to many different categories yet are defined by none of them. Nor it is morally respectable to demand 'balance' in social goods while happily acquiescing in imbalance in social bads.

Gender equality demands an end to gender-as-moral status. Yet it is the continuation, in a new form, of gender-as-moral status that much feminism implicitly or explicitly demands. It is trapped by its nature as an explicitly gender-specific perspective. It must demand that gender should not matter while proclaiming in its very title that it does.

\section{The Nature of the Human}

It is highly likely that humans are 'hardwired' to identify with groups. It is part of our sociability (Wilson, 1993). However, like most biological influences on us, it is not determinative. The group identification is 'free floating'; in modern society, we belong to many groups and move between them as appropriate. The salience of particular group memberships will fluctuate depending on a wide range of factors. Political leaders can make particular group dimensions more or less salient. The travails of the former Yugoslavia flow from utterly calculated attempts to make ethnicity politically defining. There was no necessity (historical or otherwise) here: it came from deliberate, calculated acts.

We are not defined by our group memberships, though we can diminish ourselves, and others, by acting as if we are. Terrible things lie that way, as this century tells us with particularly horrible force.

All heirs, lapsed or otherwise, of the Abralamic tradition need to face the fact that there are deep aspects in our culture that make it easy to lapse into that sort of thinking. (Equally, there are other aspects that lead firmly away from it.) Much social thinking which seems so new and radical turns out, on closer inspection, to be reworkings of old ideas, attitudes, notions of the world and our place in it. The sexual restrictionism of a Catherine MacKinnon or Andrea Dworkin is hardly without direct resonance to the anti-sex, contemptus mundi attitudes within Christianity, particularly as exemplified in the Puritan tradition which has been such a powerful element in the psyche of the United States, just as the anti-censorship feminists' favourable attitude to sexual expression is hardly without echoes of the pagan-classical tradition.

The notion that there is a single, proper image of the human, divergences from which are 'lesser', is a very powerful one. The Biblical notion that we are made in 
the image of God has typically been interpreted in terms of the existence of a form of the human (the male) which is closest to God, the others being 'lesser' as they move away from that more perfect rendering of the image. The Catholic interpretation of the Incarnation is even more powerful and more specific on this point. Male celibates are the form of the human that approach closest to God, as only they can speak for Him. Other forms are lesser. Some are sinful. 'Equal in the sight of God' is a claim not without power in Catholic theology, but the functional reality is deeply hierarchical (Wamer, 1983; Pagels, 1990; Haskins, 1993). This idea of the single blessed form is so powerful that it has been secularised and adopted in even overtly anti-Christian forms (for example, as New Soviet Man). Self-identification gives it emotional power (in these cases, for men). It is clear enough that many forms of feminism have fallen into the same trap of grading humans by group, and finding their own to be especially morally blessed.

Yet even in terms of its original conception, the idea is dubious. That the image of God can be captured, or even best expressed, within a single human type is surely nonsensical. If humans are made in the image of God, then we are each shards of the image of God, all part of the reflection in all our diversity. That diversity precludes there being a definitive human experience or perspective. It is not that reality eludes us; it is that our individual perspectives are in, some important sense, always partial, incomplete. To both grasp this, and yet not fall into an empty relativism, is a balancing act not without a certain difficulty. A true exploration of the human requires a commitment to the conversation of humanity: a confidence in ourselves, yet an opemness to the views and perspectives of others. This enriches us, just as a strident insistence on sole or dominant legitimacy for a particular perspective diminishes us.

If we are going to find a moral discourse that involves and entangles us all in the webs of obligations, rights, responsibility and duties, then it is going to have to be a common moral discourse that accepts the fact of our diversity. And it is also going to have to be a discourse that does not diminish us by seeing us as defined by one of the categories we happen to belong to. This, in turn, means that it is going to have to be, in some important sense, an ethically individualist discourse. After all, by now we well and truly know where the alternatives lead. Yugoslavia and Rwanda remind us vividly.

Feminism has certainly been a necessary part of the journey. It is not the end point, however, and its current travails, as expressed by the recent flowering of female criticism, are, to a very large degree, the result of failing to see that it is not an end point. 


\section{References}

Denfeld, R. (1995), The New Victorians: A Young Woman's Challenge to the Old Feminist Order, Allen \& Unwin, Sydney.

Farrell, W. (1994), The Myth of Male Power: Why Men are the Disposable Sex, Random House, Sydney.

Gatens, M. (1991), Feminism and Philosophy: Perspectives on Difference and Equality, Polity Press, Oxford.

Harris, M. (1990), Our Kind: Who We Are, Where We Came From and Where We Are Going: The Evolution of Humau Life and Culture, Harper Perennial, New York.

Haskins, S. (1993), Mary Magdalen: Myth and Metaphor, Harper Collins, London.

Pagels, E. (1990), Adam, Eve and the Serpent, Penguin, Harmondsworth.

Paglia, C. (1991), Sexual Pessonae: Art and Decadence from Nefertit to Emily Dickinson, Penguin, Harmondsworth.

— (1993), Art, Sex and American Culture: Essays, Viking, London.

— (1994), Tramps and Vamps: New Essays, Viutage, New York.

Rimmer, S. (1995), 'Attaining Equity: An Assessment of Federal Govenument Programs', People and Place 3(3): 16-23.

Roiphe, K. (1994), The Morning After: Sex, Fear and Feminism, Hamish Hamilton, London.

Sommers, C. Hoff (1994), Who Stole Feminism?: How Women have Betrayed Women, Simon \& Schuster, New York.

Taylor, J. Kennedy (1992), Reclaiming the Maüıstream: Individualist Feminism Rediscovered, Prometheus, Buffalo.

Thomas, D. (1993), Not Guilty: Men: The Case for the Defence, Weidenfeld \& Nicholson, London.

Travis, C. (1992), The Mismeasure of Woman, Simon \& Schuster, New York.

Wanner, M. (1983), Alone of All Her Sex: The Myth and The Cult of the Virgin Mary, Vintage, New York.

Wilson, J. (1993), The Moral Sense, Free Press, New York.

Wolf, N. (1993), Fine with Fire: The New Female Power and How it Will Change the 2Ist Century, Chatto \& Windus, London.

The author thanks David Henderson and a referee for their helpful sugzestions. 